\title{
Psychosocial impacts of quarantine among survivors of the Nipah virus infection: a qualitative study
}

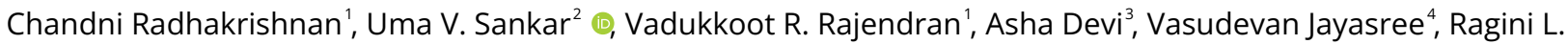 \\ Saritha ${ }^{4}$, Ayshabeevi R. Beevi ${ }^{5}$, Nochikattil Santhosh Kumar ${ }^{2}$ \\ ${ }^{1}$ Government Medical College, ${ }^{2}$ MVR Cancer Centre and Research Institute, ${ }^{3}$ Department of Health Services, ${ }^{4}$ District Medical Office, ${ }^{5}$ Department \\ of Medical Education \\ Keywords: survivors, psychosocial impacts, quarantine, nipah virus \\ https://doi.org/10.29392/001c.28993
}

\section{Journal of Global Health Reports}

Vol. 5, 2021

\begin{abstract}
Background
Quarantine is one of the best measures to prevent the community spread of any infectious diseases. The study focused on the psychosocial impacts of quarantine among the survivors of the highly fatal viral disease, Nipah virus infection (NiV), and their family members. Objective of the study was to examine the psychosocial impact of quarantine on $\mathrm{NiV}$ survivors and families being quarantined because of exposure to NiV infection.
\end{abstract}

\section{Methods}

We used qualitative in-depth interviews, Focus group discussions and Narratives of a participant observer to explore the psychosocial impacts of Quarantine during the NiV outbreak. We identified 2 major themes for doing the in-depth interview and focus group discussions: (i) quarantine experience, (ii) its impact on the family and social living and subject's working environment.

\section{Results}

The identified major themes are the following, Stroke on the community structure, public mistrust, psychosocial sequelae experienced by the grass root level health care workers, stigma in the community and social percussions.

\section{Conclusions}

Quarantine measures were effective when controlling an infectious disease spread, but it imparts many long lasting consequences on the psychological and social wellbeing of the individual. Better understanding these consequences will help to plan interventions incorporating this knowledge in future outbreaks of similar types.

Nipah virus (NiV) infection is a zoonotic infection that causes acute respiratory distress syndrome, encephalitis, and/or seizures and the mortality rate is estimated at between 40 and 75 percent. ${ }^{1}$ An outbreak was reported in both Kozhikode (Calicut) and Malappuram (Northern part - Malabar region) districts of Kerala in the year 2018. During May 3-29, NiV infection was confirmed in 18 patients, linked to the initial probable case-patient, through detection of NiV RNA by reverse transcription polymerase chain reaction (RTPCR) of throat swab, urine, or blood samples. Sixteen patients with laboratory-confirmed $\mathrm{NiV}$ infection were died (case-fatality rate 89\%) in this outbreak. Although the source of infection for the initial case remained unknown, all subsequent cases occurred by person-to-person transmission through close contact with NiV patients. ${ }^{2}$ As part of contact tracing, district health authorities identified $\approx 2,600$ contacts of laboratory-confirmed NiV patients. Contacts were monitored for 21 days post-exposure for development of febrile illness. Early supportive care and treatment of symptoms improves survival, though there is currently no definitive treatment for Nipah. 2,3

Over the decades, quarantine and isolation have been widely used to control the spread of numerous communicable diseases. Quarantine refers to restricted movement of those who have been exposed to a contagious disease but who may or may not become ill, whereas isolation applies to restricted movement of persons that are known to be ill with a contagious disease. ${ }^{4}$ Modern quarantine includes a range of disease control strategies that may be used individually or in combination, including; short-term voluntary home curfew, restriction on the assembly of groups of people, cancellation of public events, closure of mass transit systems, and other restrictions of travel. All these measures have multiple psychosocial impacts upon patients, their families, workplaces and communities. ${ }^{5}$ Patients with NiV during the isolation period reported fear, loneliness, boredom, and anger and they worried about the effects of quarantine and contagion on family members and friends. 
Identifying a greater number of close contacts of NiV diagnosed subjects made the public to become fearful. ${ }^{6}$ Health care workers were also adversely affected by fear of contagion and of infecting their family members, friends, and colleagues. By being quarantined in a society, the traumatic, psychological and social effects will be shared by a group of people of any size, up to and including an entire society. ${ }^{6-8}$

Little is known about the psychosocial effects of this type of disease outbreak on the NiV disease survivors and their family members, who would be quarantined during the NiV infection. The objectives of the study are to assess the selfreported psychosocial impacts associated with quarantine of NiV disease among the NiV disease survivors and the families being quarantined during the disease outbreak and to examine the determinants of these psychosocial impacts.

\section{METHODS}

\section{STUDY SETTING}

We performed the qualitative study at two different settings of the affected locality. One was performed in the community premises of the affected area of Kozhikode (Calicut) and Malappuram. The second setting was in hospital premises of the principal primary care institutions of the affected locality namely Community health centre Perambra, Kozhikode and the principal tertiary care setting Government Medical College, Kozhikode (Calicut), Kerala (community transmission happened in these two health care settings).

\section{SUBJECTS}

To assess the psychosocial impacts of the NiV infection at the individual level, we considered three groups: Survivors, contacts and carers.

1. Survivors: Those who survived with NiV disease. We interviewed both NiV survivors for the study.

2. Community contacts: The family members, friends and close/immediate relatives of NiV subjects. Community contacts were defined as closest level of exposure to the index case is more than or equivalent to 30 minutes within the distance of 1 metre. ${ }^{1}$

3. Carers: Family Care givers and Health care workers who were taken care of the NiV subjects. Family care givers included the siblings, spouse, parents, uncles, aunts and cousins. Health care workers included emergency medicine and general medicine specialists, residents, nurses and ASHA (Accredited Social Health Activist) workers in the community. We interviewed 8 community contacts, 5 health care workers and 7 family carers of NiV subjects and one stakeholder. We began the data collection in June, 2019 when the quarantine efforts in Northern districts were being completed.

\section{ETHICS}

Institutional ethics committee approval was obtained for the conduct of the study. Participation in the study was en- tirely voluntary. We provided all the participants with an information sheet written in their native language [Malayalam] and informed them of the purpose, nature, and procedure of the study. We had completed the informed consent process before the start of the interview.

\section{QUALITATIVE METHOD}

Three types of qualitative techniques were employed in this study.

1. Fourteen in-depth interviews with the NiV survivors and carers.

2. Two Focus group discussion among the community contacts (included the accredited social health activist - ASHA workers).

3. Narratives of a stake holder/ participant observer.

\section{INTERVIEW TECHNIQUE}

We conducted the interviews lasting average 1 hour 21 minutes each (ranging from 35 minutes to 1 hour 40 minutes). The interviews were in the following 2 major themes: (i) quarantine experience, (ii) its impact on the family living, social living and working environment. These themes were emerged from the freewheeling interviews with the community contacts prior to the study. We interviewed Nipah survivors and 12 subjects in person (face to face) interviews. The interview guide was used throughout the interview process to guide the discussion and to ensure that the interviews did not deviate from the research questions. One of the investigator (UVS) conducted all the interviews to maintain consistency and to ensure consistent interview quality. This approach also minimized the risk of data variations and data flaws that might have resulted from introducing another interviewer. We used "stimulation recall" to prompt interviewees or subjects in informal discussion concerning specific events. We asked general questions initially before moving to sensitive or specific questions to avoid question-order bias of the researcher.

\section{ANALYSIS}

A narrative analysis approach was also used to discover themes and recurring structures within the informants experiences. ${ }^{9}$ This approach facilitated identification of patterns and characteristics of the study cohort as seen by both faculty and student populations. After the transcription of the data, we worked closely and intensively with the text, annotating it closely ('coding') for insights into the participants' experience and perspective on their world. ${ }^{10}$

We summarized ideas that addressed important themes using the multiple respondents and data sources to crosscheck for validity and enrich the interpretation of data till the data saturation. Direct interview quotations were included in the coding analysis to avoid researcher bias, motivation, or interest in the analysis, and to establish credibility and neutrality and enabling the findings to be grounded in the data. Recoding was conducted one month after the first coding session, with cross-checking to enhance the validity and reliability of the data and findings and to ensure the elimination of subjectivity and bias. 


\section{Box 1. Questions in the interview guide}

1. How did you feel the quarantine experience? (ill feeling/tensed/ time to enjoy/Your activities)

2. How did you know the updates/ NEWS during that time?

3. What was your experience with your closed one's, friends / families during the time? (family role, social role, parental role).

4. What were the major hurdles you have been faced to go back to the new 'old' life? (to go back to regular normal life).

\section{Box 2. Questions in the focussed group discussion (FGD) guide}

1. How. did you know about the NiV disease? (your first experience of hearing a new disease)

2. How was the neighbourhood community /village response to this outbreak?

3. What was your feeling when you travelled from your place during the outbreak was on and off (decreased)?

4. Did you experience any difficulty during the quarantine? If yes, what was the major constraint you had faced during the quarantine?

\section{NARRATIVES OF PARTICIPANT OBSERVATION}

First author was the head of the department of emergency medicine of the tertiary care centre of the affected region. She was actively involved in the patient management and preventing the spread of the disease and had the opportunity for community visits in the affected locality.

\section{RESULTS}

\section{SURVIVORS}

$\mathrm{NiV}$ infection is a contagious disease with life threatening clinical manifestations and high case fatality rates. Those affected are likely to experience psychological effects due to the infection, fear of impending death and the experience of witnessing closed ones dying. The affected persons can experience psychosocial impacts due to feelings of shame or guilt (e.g. from transmitting infection to others) and stigmatization or blame from their communities.

\section{COMMUNITY CONTACTS}

Contacts of those infected with NiV infection also may experience stigmatization and isolation. Witnessing the course of the infection in others can result in fear and anxiety about falling ill or dying themselves, in addition to feelings of loss and grief from losing loved ones. Since NiV is transmitted through contact with bodily fluids, loved ones are often separated from the sick upon showing symptoms and are unable to be with them while they suffer or die. This can increase feelings of grief, loss or distress and feelings of guilt or helplessness for being unable to comfort or give care to their loved ones. In the authors' experiences, quarantining protocols though essential to reduce the NiV transmissions, have also led to stigma and community isolation.

\section{CARERS}

Family caregivers had significant physical contact with the affected patients until the confirmation of the disease. Most of the patients (80\%) had high grade fever and fatigue as early symptoms. The family care givers gave tepid sponging (sponging the whole body with lukewarm water to reduce the temperature of the body) thrice a day and assisted them to feed the rice porridge (Kanji). They also cleaned the vomitus and other secretions with bare hands without any protection. But once the NiV infection was confirmed, the hospital staff did these jobs with adequate protection wearing personal protection equipment.

There was a risk of transmission of the disease even after the death. The traditional mourning practices, which involved cleaning and touching the corpse while preparing them for burial, according to the customs as per the culture and religion were unsafe. So such practices were avoided. In all cases, the corpses were buried by people trained in proper infection control practices to prevent further transmission, which might compound the loss experienced by loved ones. The sociocultural and religious practices and rituals after death, before cremation could not be met in those times and also the community gatherings and prayers as per the cultural practices could not be convened because of social restrictions existed. These disruptions to traditional practices aroused feelings of resentment anger and fear (e.g. beliefs about misfortune when not paying respect to the deceased) among some of the close relatives. In some areas that affected the community support badly. The sudden unexpected demise of the loved ones needed psychosocial support. But the lack of such resources to the extent needed and their isolation or quarantine actually added to their distress. The prohibition of the conventional death rites aggravated the situation.

\section{FEAR ABOUT UNKNOWN DISEASES}

The Lack of control over the disease and the indecorous atmosphere made the people more and more anxious and worried.

An autorickshaw driver recollected those days:

"I am an auto driver. We were only 6 to 10 auto rickshaw drivers in that area. Usually when we used to meet after a ride at our parking slot, we used to talk loudly, make fun of each other, laugh loudly. But we were not able to utter even few words. There was a fearful loud Silence between 
us. If somebody coughed, we used to move away from them and that place and some of us even refused our service to them. We were extremely scared".

Another member in the community said:

\begin{abstract}
"Even the highly educated medical community were not aware of the management of NiV being a new disease. The site of doctors and other health care professionals with their PPE kit and other extensive protective measures increased our anxiety and distress. We had never witnessed such a situation in our life. The authorities were fumbling around in the dark to control the NIV. There were no information regarding the control or the prognosis of the infection during the initial period of the outbreak. Only information was the infection is fatal. Uncertainty and fear prevailed in the community. We didn't know what to do."
\end{abstract}

The anxiety and fear affected the personal relations badly. Many of them could not sleep during the night and they were sitting at home during the day time without knowing what to do. They were afraid of each other and they avoided people with fever or cough. They didn't want anybody to come home. Some of them went to relative's house at distant places. But they didn't get a warm welcome. Some of them even denied to open the door to welcome them.

\section{STIGMA IN THE COMMUNITY}

Health care workers interviewed. ASHA workers in the locality experienced stigma as a result of their exposure to $\mathrm{Ni}$ pah outbreak. One of the ASHA workers told that "People didn't wanted us to go near them". Another ASHA worker said:

"I felt bad when one of my neighbour shut their doors and asked their kids to get inside the house, when they saw me walking through the road in front of their house."

Another health care professional added:

| "People stopped talking to me and my family."

One of the community members in the interview said:

"Even after the outbreak was contained and the quarantine was over, I was afraid to tell the people that I am from the affected village." Another member in the community said "He visited the nearest health centre for cold and fever, somebody in the queue told him to stay away from the queue, because he was from the affected village."

\section{PSYCHOLOGICAL SEQUELAE EXPERIENCED BY GRASS ROOT LEVEL HEALTH CARE WORKERS}

One of the ASHA workers told us:

"I felt helpless and depressed. I couldn't sleep properly and I was always thinking about death. I was crying the whole day without any reason and my family was also worried about me. This got aggravated when one of the sister contracted the infection and died."

Another community volunteer told us:

"My wife was very upset and angry towards me. She was accusing me that I was not taking proper care, that is why
I had contact with a Nipah victim. She experienced anxiety, shortness of breath, sleeplessness and headache.. She was not willing to go to bed as she could not sleep and if she slept she was having nightmares.”

\section{PUBLIC MISTRUST}

Families of NiV cases and community residents were not ready to accept that the fever spread originally from bat. According to them bats were a group of harmless animal found very commonly in their area. One of the community member told that:

"At least 200 bats are there in my well. We are drinking and using water from the well for more than 50 years. But we never had any problem so far."

Family members of the index case and subsequent initial cases, considered the illness as a "normal fever." They had mistrust when modern medicine and hospitals with all intensive care facilities failed to save their life. Once the diagnosis of the index case was confirmed as NiV infection, they realised that they are facing an illness without medicine.

The confusions regarding the source of infection and the paranoids in the social media created a panic situation among the public during the initial days of the outbreak. One family member told that:

\begin{abstract}
"Newspapers brought us only assumptions and speculations about the source. They wrote eating imported dry fruits like dates could be the reason for the Nipah outbreak. Another media wrote it is transmitted from raw banana or bat bitten mango." Another community member reported that "we were afraid to eat all fruits and vegetables due to the fear of Nipah. It was a mango and jack fruit season, but we didn't eat even those fruits from our own trees. If we open the WhatsApp, we will never take anything raw."
\end{abstract}

One of the ASHA workers told that:

"Even though the technology is advanced this much, no medicine for a disease. I cannot believe this. Every year, we used to hear some new disease or fever with new name. I don't think it is natural, but is manmade."

\section{COMMUNAL CONSEQUENCES OF SOCIOECONOMIC DOWNTURNS}

At the community level, a cyclical pattern of fear happened, with loss of trust in health care services and stigma initially. But with proper interventions in the community by different means, the authorities could gain trust and cooperation from the community. The system got ready to accept the isolation and quarantine procedures. The initial mistrust resulted the disruptions in the community interactions and temporary reallocation of the households, which led to community fracturing. A communal sense of grief also developed as initially the infected cases and death were from a particular religion. But the health care authorities through appropriate interventions and education could manage it well and it was sorted out at the initial stages itself.

We noticed different type of psychosocial consequences 
in the families who lost their bread winning member due to the infection. They had to shift their roles to replace the loss of parents and bread winners.

A person who lost her immediate relatives before us:

\begin{abstract}
"Remembering those days makes me cry. I lost my elder son, for whom I gave my breast milk for the first time and loved more than me. He used to take care of my health and all house hold jobs. He used to manage our guests. He used to help my younger daughter financially and physically for constructing a new home. I was not completely recovered from his demise, when I lost my second son and my husband. How can I forget or sleep properly after losing three loved ones. The God is experimenting on me... But I am lost. I just don't feel anything now."

"After I lost them, nobody visited me, no one was there to console me. I wanted to cry out to someone, so that I would have felt little better. But nobody came in. Everybody was afraid of the illness and they would have feared talking to me or coming near me will transmit illness to them. Nobody asked about our needs and worries. I tried to sell this property, but nobody came forward to buy. ASHA worker was the only person who visited me frequently and asked about my health and needs."
\end{abstract}

The loss of family members and associated quarantine regulations made the situation worse. They were mentally and emotionally broken. There were no adequate interventions or facilities to address these issues. The community faced structural repercussions including loss or closure of an existing business, closure of community services, markets and schools, less usage of health and supportive care services, irreparable damages to real estate sector and regular jobs.

\section{SOCIAL PERCUSSIONS}

The economic and social challenges followed the endemic. The families who had victim or were quarantined were discriminated by nearby villagers. People from other villages were reluctant to have marital relations from the affected village and they also faced difficulty to sell land and other things. Some marriages which were fixed before the endemic, got cancelled. Some people considered it as "God's curse" to these villagers. One of the major state highways passed through the village $\mathrm{X}$ and the vehicle density was also very high before the outbreak. But after the outbreak, the number of vehicles passing through this village came down drastically and people chose an alternative road.

An ASHA worker told us:

"A Father was committed suicide due to the cancellation of marriage of his daughter. He was a retired teacher and he had planned to sell his land to meet the expense of daughter's marriage. But it didn't happen."

The ward member (community leader of the single rural administrative unit/ward) told us:

"It is very sad to say that the cost of land in village $X$ fell from around 1,00,000 Indian Rupees (INR)/unit in pre-outbreak period to 20000 INR/unit. There were many street vendors by the highway road. All of them stopped their sales due to the less vehicle usage of the state highway".

\section{DISCUSSION}

This study has documented the living experiences of Nipah survivors and the people who were quarantined during the Nipah outbreak. The NiV outbreak of 2018 had produced profound psychosocial implications at individual and community levels. An earlier study has emphasized the need for addressing the psychological issues during and after isolation. ${ }^{11}$ It is as important as screening for the illness among the isolated individuals. Response efforts should involve communities to address psychosocial needs, to rebuild health systems and trust, and to limit stigma. This is already been studied and documented with Ebola infection. ${ }^{7}$ The effects could be acute or long term and spreading over individual, community and international levels.

Lack of control and predictability of an unknown disease made the public go panic and anxious. Effective communication strategies through the community leaders should reach to the lay persons to reduce the seclusion of affected community and control other negative social percussions. ${ }^{3,12}$

Integrating local knowledge and understanding of illness with biomedical approaches to achieve culturally relevant, acceptable and appropriate psychosocial interventions is essential. ${ }^{12}$ Strategies include communication, education, community engagement, peer support, resource mobilization and prevention activities (e.g. risk assessment, psychosocial support) as well as mental health care. Interventions and policy initiatives should embrace survivor engagement to solicit and learn from their experiences, to influence policy and practice, including efforts to address physical, psychological and social care needs (e.g. stigma and re-integration). $9,10,12$

It is important that the discourse and implementation of strategies addressing needs resulting from the epidemic should not further marginalize or stigmatize affected communities. Such marginalization is compounded by a focus on factors exacerbating the epidemic and weaknesses in these communities, rather than their strengths (e.g. social resources or resilience), which not only dis-empowers them but also inhibits the success by failing to integrate to the existing resources.

We should also recognize existing efforts that address psychosocial effects of the outbreak, for example mental health training for health workers, psychological first aid and significant support from within communities and the global community such as donations, volunteers, community mobilization, peer support and awareness-raising. The study also sought to connect with stigma associated with 'an unknown disease'. The stereotyping (associating some adverse social and cultural attribute with the identified unknown condition) and 'othering' (differentiation of people with attribute "them", very different from "us" happens and finally loss of social status and discrimination happened in this case. However, significant void remains in addressing the psychosocial care after the NiV outbreak, as requested by many survivors. Psychosocial care has been insufficient to date due to a lack of resources, overburdened health systems and a lack of knowledge about the supporting psychosocial needs whenever a new outbreak comes. During this NiV outbreak, a psychological intervention strategy 
was incorporated by the District Mental Health Programme, Calicut. ${ }^{8}$ But the present study tells clearly that there should be continuous long-term strategies targeting those people who directly received the major brunt of such outbreaks.

\section{CONCLUSIONS}

A multi-faceted approach is needed to address the psychosocial consequences of similar epidemics at individual, community, national and international levels. The psychosocial effects of the outbreak, and subsequent lessons learnt, should not only inform acute responses to $\mathrm{NiV}$, but also the development of health systems and strategies to respond to future $\mathrm{NiV}$ or similar epidemics. Lessons learnt from previous responses to such crises by the global community and regulations (both beneficial and ineffective strategies) should be revisited in formulating responses to $\mathrm{NiV}$ or similar type of epidemic. Initiatives providing psychosocial support should integrate and strengthen traditional, social and psychological support structures, while recognizing resilience and drawing on positive empowering resources existing within communities.

\section{ACKNOWLEDGMENTS}

To all study participants especially the emergency medicine consultants, Post Graduate Students, Nipah survivors, ASHA workers, Health inspectors and community volunteers for their patience to respond to our repeated queries.

\section{DISCLAIMER}

This research article represents the opinions of the study participants, and is the product of professional research. It is not meant to represent the opinions of any of the authors, nor the official position of any authors.

\section{ETHICS}

Approval was granted through the institutional ethics Committee of Government Medical College, Calicut, Kerala (Ref No. GMCKKD/RP2019/IEC/164).

\section{FUNDING}

None.

\section{AUTHORSHIP CONTRIBUTIONS}

CR-Conception of the proposal, data collection, interpretation and drafting of the article. UVS- Conception, design of the proposal, data collection, interpretation and drafting of the article. VRR, AS, JV, SRL \& RBA- Drafting and critical revisions of the article. SKN - Data collection and drafting the article

\section{COMPETING INTEREST}

The authors completed the Unified Competing Interest form at http://www.icmje.org/disclosure-of-interest/ (available upon request from the corresponding author), and declare no conflicts of interest.

\section{CORRESPONDENCE TO:}

Uma V Sankar, MPH Ph.D, Senior Research Coordinator, MVR Cancer Centre \& Research Institute, Kozhikkode, Kerala. India.673601.E mail; umasanthosh23@gmail.com

Submitted: July 02, 2021 GMT, Accepted: September 14, 2021 GMT 


\section{REFERENCES}

1. Chadha MS, Comer JA, Lowe L, et al. Nipah virusassociated encephalitis outbreak, Siliguri, India. Emerg Infect Dis. 2006;12(2):235-240. doi:10.3201/eid $\underline{1202.051247}$

2. Arunkumar G, Chandni R, Mourya DT, et al. Outbreak Investigation of Nipah Virus Disease in Kerala, India, 2018. J Infect Dis.

2018;219(12):1867-1878.

3. Yadav PD, Shete AM, Kumar GA, et al. Nipah Virus Sequences from Humans and Bats during Nipah Outbreak, Kerala, India, 2018. Emerg Infect Dis. 2019;25(5):1003-1006. doi:10.3201/eid2505.181076

4. Cetron M, Maloney S, Koppaka R, et al. ISOLATION AND QUARANTINE: CONTAINMENT STRATEGIES FOR SARS 2003. In: Knobler S, Mahmoud A, Lemon S, et al., eds. Institute of Medicine (US) Forum on Microbial Threats; Learning from SARS: Preparing for the Next Disease Outbreak: Workshop Summary. National Academies Press (US); 2004.

5. Van Bortel T, Basnayake A, Wurie F, et al. Psychosocial effects of an Ebola outbreak at individual, community and international levels. Bull World Health Organ. 2016;94(3):210-214. doi:10.2471/ blt.15.158543

6. Robertson E, Hershenfield K, Grace SL, Stewart DE. The psychosocial effects of being quarantined following exposure to SARS: A qualitative study of Toronto health care workers. Can J Psychiatry. 2004;49(6):403-407. doi:10.1177/07067437040490061 $\underline{2}$
7. Van Bortel T, Basnayake A, Wurie F, et al. Psychosocial effects of an Ebola outbreak at individual, community and international levels. Bull World Health Organ. 2016;94(3):210-214. doi:10.2471/ blt. 15.158543

8. Swathy SS, Sidharthan M, Issudeen M, Shibukumar TM, Kumar A, Tharayil HM. Psychological Interventions During Nipah Viral Outbreak in Kozhikode District, 2018. Indian J Psychol Med. 2018;40(4):387-389. doi:10.4103/ijpsym.ijpsym_249_1 $\underline{8}$

9. Smith JA, Flowers P, Larkin M. Interpretative Phenomenological Analysis: Theory, Method and Research. SAGE; 2009.

10. Bernard RH. Research Methods in Anthropology: Qualitative and Quantitative Approaches. Rowman \& Littlefield Publishers, Inc; 2011.

11. Kannampulakkal SM, Sudevan SS, Tharayil HM, Radhaskrishnan C. Psychosocial Effects of Isolation on Nipah Virus Infection Suspects During an Outbreak. JAPI. 2020;69:41-45.

12. Babalola E, Noel P, White R. The biopsychosocial approach and global mental health: Synergies and opportunities. Indian J Soc Psychiatry. 2017;33(4):291-296. doi:10.4103/ijsp.ijsp 1317 